\title{
Studying Peace and Studying Conflict: Complementary or Competing Projects?
}

\author{
John Gledhill (Forum Coordinator) and Jonathan Bright
}

\begin{abstract}
Peace' and (violent) 'conflict' are often seen as conceptual mirror images of one another; peace is the absence of conflict, and conflict is the absence of peace. Given this conceptual interdependence, some scholars see that the study of war/making and the study of peace/making are complementary - or even functionally identical - academic projects. Others, however, see that studies of violence and warmaking are antithetic to studies of peace and peacemaking. The six contributions to this JoGSS Forum explore these contrasting perspectives, with a view to assessing the 'state of the discipline' of peace and conflict studies (and cognate disciplines, such as security studies). The introduction offers provocations for debate. The two contributions that follow consider connections and disconnections between the study of conflict and studies of post-conflict peacebuilding and transitional justice, respectively. The next two contributions focus on areas of investigation that do not fit neatly into either the 'peace' or 'conflict' categories - Gender, and Nonviolence - and the authors explore how studies of these topics might create bridges between scholarship on peace and studies of violent conflict. The concluding contribution argues that 'mainstream' peace and conflict research has come to be dominated by positivist treatments of war and violence, and it draws attention to alternate approaches that have the potential to transform and ameliorate social relations.
\end{abstract}

FORUM for publication in the Journal of Global Security Studies (2019)

John Gledhill is Associate Professor of Global Governance in the Department of Internationa 1 Development, University of Oxford.

Jonathan Bright is Senior Research Fellow at the Oxford Internet Institute, University of Oxford. 


\title{
FORUM
}

\author{
Studying Peace and Studying Conflict: Complementary or Competing Projects? \\ John Gledhill (Forum Coordinator) and Jonathan Bright
}

\begin{abstract}
Peace' and (violent) 'conflict' are often seen as conceptual mirror images of one another; peace is the absence of conflict, and conflict is the absence of peace. Given this conceptual interdependence, some scholars see that the study of war/making and the study of peace/making are complementary - or even functionally identical - academic projects. Others, however, see that studies of violence and warmaking are antithetic to studies of peace and peacemaking. The six contributions to this JoGSS Forum explore these contrasting perspectives, with a view to assessing the 'state of the discipline' of peace and conflict studies (and cognate disciplines, such as security studies). The introduction offers provocations for debate. The two contributions that follow consider connections and disconnections between the study of conflict and studies of post-conflict peacebuilding and transitional justice, respectively. The next two contributions focus on areas of investigation that do not fit neatly into either the 'peace' or 'conflict' categories - Gender, and Nonviolence - and the authors explore how studies of these topics might create bridges between scholarship on peace and studies of violent conflict. The concluding contribution argues that 'mainstream' peace and conflict research has come to be dominated by positivist treatments of war and violence, and it draws attention to alternate approaches that have the potential to transform and ameliorate social relations.
\end{abstract}

\section{Introduction}

If peace is commonly seen as the absence of war, and war is the absence of peace (Galtung 1985, 145; Klein et al. 2008, 67), then the study of peace and the study of violent conflict effectively amount to one and the same thing. At least, this logic underwrote the establishment of 'peace and conflict' studies as an academic discipline in the 1950s. That initiative brought together scholars who had diverse disciplinary backgrounds but, nevertheless, shared a common commitment to scientifically studying the causes and dynamics of armed conflict, with a view to identifying reforms that could contribute to the peaceful management and resolution of conflicts (see Kelman 1981; Wallensteen 2011; Regan 2014). Despite an early commitment to linking the study of warmaking with the praxis of peacemaking, there has long been concern that the study of peace and conflict is divided between works that unpack the causes of war and violence, on one side, and studies of efforts to prevent or respond to violence, on the other (see divisions discussed in Buzan and Hansen 2009, ch. 5; Lopez 1985; Vasquez 1976). That is, there has long been suspicion that the field should be described as 'peace or conflict' studies, rather than 'peace and conflict' studies. In the six contributions to this JoGSS Forum, we investigate that suspicion and, in so doing, 
consider whether the study of peace and the study of violent conflict are complementary or competing academic projects. ${ }^{1}$

Our investigation of the 'state of the discipline' is not simply an exercise in academic introspection. Rather, by looking at the nature of intellectual connections and disconnections within peace and conflict studies (and cognate disciplines such as security studies) ${ }^{2}$, we aim to contribute to broader debates over whether scholars of peace and conflict are collectively realizing the founding normative goal of their discipline(s) which, as suggested, was to contribute to an understanding of how conflict can be managed peacefully. While that goal took shape as a response to the horrors of the Second World War and the dangers of Cold War nuclear confrontation, it is an aspiration that remains as meaningful and important today as when the field was first established. It is also a goal that need not undermine the possibility of objective empirical analysis; it is perfectly possible to conduct objective studies of war/making and peace/making even while recognizing that the ultimate aim of those studies is to contribute to the realization of a common - pacific - good (Regan 2014, 353).

Scholars in the medical sciences adopt this model of empirical study aimed at an ameliorative end and, for that reason, comparisons have sometimes been drawn between the study of medicine and the study of peace and conflict (Galtung 1985; Wallensteen 2011, 17). In both fields, some lines of research seek to isolate the causes of 'disease', while other research explores possible 'remedies'. And, in both fields, the (assumed) collective aim of scholars is to identify, and then prescribe, the most efficacious of those remedies. Intuitively, such a goal can only be realized if those who work on the causes of disease engage with those who work on remedies. Within the medical sciences, such intellectual exchange arguably exists. However, there has been - and remains - concern that scholars of peace and conflict tend to operate in intellectual siloes, so that there is only limited exchange between studies of conflict dynamics and studies of conflict prevention/response. If that is indeed the case, then we may have reached a point where we collectively know a lot about war, and a lot about peace, but little about the

\footnotetext{
${ }^{1}$ A number of the contributions to this Forum originated out of the 2016 OxPeace Conference, held at the University of Oxford on 14 May 2016. We thank contributors, participants, and organizers of the conference. We also thank anonymous reviewers and the editors of JoGSS for their comments on earlier drafts of these papers.

2 Throughout this introductory piece, we refer to studies that address issues of violent conflict, war, collective violence and/or efforts to prevent or respond to such conflict as examples of 'peace and conflict studies'. We use this term in a way that is largely interchangeable with 'security studies'. While we recognize that some scholars may critique this similitude, we adopt it here, arguing that early conceptual(and possibly normative) boundaries between 'security studies' and 'peace research' weakened after the Cold War (see Buzan and Hansen 2009, 1319). As such, scholars of 'peace and conflict studies' and 'security studies' - both broadly understood - now often investigate similar sets of topics.
} 
connection between the two. Concern over this possibility has recently led several senior scholars to start a conversation about whether the academic study of peace and conflict may have lost sight of its founding goals (Regan 2014; also Diehl 2016). The contributions to this Forum contribute to this conversation.

The remainder of this introductory piece lays a platform for the focused studies that follow by making some empirical observations about the 'state of the discipline' and offering provocations for debate. In the next section, we sketch existing efforts to map peace and conflict studies and add our own novel contribution to those efforts. We then consider what this mapping tells us about the evolution of peace and conflict studies, and offer reflections on how the field might move forward. Finally, we conclude by introducing the studies that make up the remainder of the Forum.

\section{Mapping the Field}

Despite the long-standing assumption that the study of peace and conflict is a divided discipline, there have been few attempts to test the validity of that assumption. One reason for the lack of testing is that the two conceptual pillars of the field - peace and conflict - are both contested terms. It is therefore difficult to categorize individual studies under either banner, as a first step toward assessing whether there is interaction and exchange between studies of peace and conflict. Consider the concept of 'conflict'. While the term is often associated with the use of violence in a struggle for power, some scholars adopt a minimal understanding of violence as force that causes physical harm ('direct violence'). Others expand the idea to include the existence of repressive social, political, and economic structures that cause harm to individuals' life chances ('structural violence') (see Bufacchi 2005; Galtung 1969). Since peace is commonly understood as the absence of violent conflict, these differing definitions of violence give rise to different understandings of peace - either as the absence of war and violence ('negative peace') or also as the absence of repressive socio-political structures ('positive peace') (see Galtung 1969; Diehl 2016). More recently, Goertz et al. (2016) have gone beyond this negative/positive binary to establish a multidimensional 'peace scale'. Setting aside discussion of the inherent merits of any of the above approaches, the mere existence of competing conceptions of peace and conflict creates complications for the discipline's potential cartographers. That said, some recent mapping efforts have used minimal understandings of 'conflict' (as violence and war) and 'peace' (as the absence thereof) as starting points for coding and analyzing scholarly output on those themes. 
In one such study, Nils Petter Gleditsch and his colleagues ask whether 'peace research' is, in practice, 'just the study of war' or whether peace researchers also investigate conditions of peace and peacemaking (Gleditsch et al. 2014). To answer this question, the authors automatically coded the content of articles published in the Journal of Peace Research and Journal of Conflict Resolution over past decades. Narrow sampling restricts the generalizability of their study, but the authors nevertheless find that works on the causes and dynamics of violent conflict have tended to dominate the publications they investigate. Studies of 'peace', on the other hand, appear more rarely in those publications and receive fewer citations. These findings are important, to be sure, but the authors have little to say on the question of intellectual exchange and connections between studies of peace and studies of conflict because they do not look at citation patterns among works that address the respective topics. Silla npää and Koivula (2010), however, have realized a study of co-citation patterns within conflictrelated research, and they find few links between studies they categorize as 'Civil War' and studies of 'Prerequisites for Peace'. Again, this finding is important, but its significance is limited because the authors only investigate the citation patterns of a relatively small sample of articles.

Given limitations of existing mapping efforts, we have been incrementally documenting scholarly output on topics of peace and conflict, using a range of methods including a survey of scholars, manual and automatic coding of the content of journal articles, and computational analysis of citation patterns. While our conclusions are qualified due to limitations of the methods we employ, they still allow us to paint a relatively clear picture of output and exchange on themes of peace and conflict.

\section{A Top-Down Approach: Coding the Content of Articles in the Field}

In one recent study (Bright \& Gledhill 2018), we take a largely 'top-down' approach, making use of a dataset that we compiled by (manually, then automatically) coding the content of 7,124 articles that have appeared in eighteen leading journals over the past two decades. Nine of those journals publish on themes of international relations generally, ${ }^{3}$ and nine are specialist journals that focus on issues of peace and (violent) conflict. ${ }^{4}$ We coded each article

\footnotetext{
3 European Journal of International Relations, Foreign Affairs, Global Governance, International Affairs, International Organization, International Relations, International Studies Quarterly, Millennium, and World Politics.

${ }^{4}$ Cooperation and Conflict, International Peacekeeping, International Security, Journal of Conflict Resolution, Journal of Peace Research, Journal of Strategic Studies, Security Dialogue, Security Studies, and Terrorism and Political Violence.
} 
as falling into one of two substantive categories: 1) 'Conflict', understood as studies of the causes and dynamics of war and other types of collective violence; and 2) 'Peace', understood as studies of conflict prevention and/or conflict responses. ${ }^{5}$

Consistent with the results of Gleditsch et al. (2014), we find that there is a large body of work that addresses 'conflict' processes. Considerably fewer articles focus on outcomes of 'peace'. We also find that 'conflict' articles, on average, receive approximately $50 \%$ more citations per year than articles coded as 'peace'. Bringing these two descriptive findings together, we conclude that studies of the causes and dynamics of violent conflict hold a dominant position in the field.

As a second step, we were interested to know whether there is engagement and interaction between studies classified as 'conflict' and those classified as 'peace', or whether the field is broadly divided. Looking at citation patterns between articles that we assigned to each of these two categories, we find qualified - though not complete - evidence of division. Overall, less than one fifth of citations in our sample run from 'conflict' to 'peace' articles, or vice versa. Significantly, we find that movement across the divide is imbalanced; studies of 'peace' tend to cite studies coded as 'conflict' to a much greater degree than the inverse. This suggests that, overall, the study of violent conflict is quite insular, while studies of conflict prevention and response (i.e. 'peace') are more outward-looking.

\section{A Bottom-Up Approach: Automatic Community Detection}

While a 'top-down' approach allows us to make broad claims about the distribution of work on themes of 'peace' and 'conflict', respectively, it does not offer insights into connections between studies of specific topics related to those themes. Such an assessment is possible, however, by using an automatic community detection technique drawn from the field of network analysis (in particular, we use a method called 'infomap'). Broadly speaking, this method examines patterns of citations between all articles in a dataset and clusters together those that cite one another frequently. ${ }^{6}$ We then give clusters labels that reflect the topical content of their constituent articles by using an algorithm that identifies words that appear particularly frequently in the titles of articles in a cluster, but less frequently within other

\footnotetext{
${ }^{5}$ For a detailed treatment of our methods and sampling techniques, see the online Appendix to Bright \& Gledhill (2018).

6 See Fortunato (2010) for an overview of community detection in general, and Rosvall et al. (2009) for a description of the infomap approach, in particular.
} 
clusters. ${ }^{7}$ Those words can be used as a basis for devising 'readable' names for clusters. It is also possible to categorize clusters into broad themes, and assess whether categories of articles on particular topics are connected (via citations) to categories that address other topics.

Figure 1 illustrates some of the output from our automatic detection and labelling of communities that exist within peace and conflict studies. It is based on citation information drawn from articles that have appeared in our eighteen selected journals over the past two decades. Since the infomap algorithm identified more than 500 individual clusters, we could not show them all. Instead, we chose to present categories that relate to the five substantive areas of peace and conflict studies that are addressed by contributors to this Forum (specifically: 'Conflict and Civil War', 'Transitional Justice', 'Nonviolent Resistance', 'Gender', and 'Peacebuilding'). ${ }^{8}$ We identified clusters of more than ten articles that we thought related to these categories, and visualized the layout of those categorized clusters in the figure. ${ }^{9}$ While we did not actively assign a code of 'peace' or 'conflict' to articles that fall within our five categories of interest, our labelling suggests that some fall on the conflict side of the peace/conflict divide (those categorized as 'Conflict and Civil War'); some fall on the 'peace' side (those labelled 'Peacebuilding' and 'Transitional Justice'); and two categories include articles that could not be easily labelled as either conflict- or peace-focused ('Gender' and 'Nonviolent Resistance').

In the figure, each point represents a single article and connecting lines between points indicate citation links between two articles. The spatial positioning of each article is determined by a layout algorithm that attempts to place articles close together if they are connected by citation links, and far apart if they are not. This arrangement allows us to visualize articles that cite one another regularly, and to show the degree to which there are connections between categories of articles that address various themes. Categories have been color- and shape-coded to facilitate interpretation.

\footnotetext{
${ }^{7}$ More precisely, words in the titles of articles in each cluster are given a 'tf-idf' score, which takes into account the number of times the word appears in the cluster, and the number of other clusters it appears in.

${ }^{8}$ It should be noted that the labelling process is only an approximate reflection of the content of articles within clusters and as sociated categories, so some articles within any given category inevitably do not focus on the topic as sociated with the category label. That said, a manual check of the titles of articles that fall within the categories we have included in this study suggests broad face validity.

9 In a supplementary online Excel file titled 'Articles', we detail: the clusters that we finally chose to include (through an iterative process); the titles of articles in those clusters; and the categorical labels that we assigned to included clusters. In the supplementary files, we also include a version of Figure 1 in which discrete clusters within each of our five categories are identified by numbers that correspond with clusters that are detailed in the supplementary Excel file.
} 
Since we only show a limited number of clusters and categories, the figure should not be seen as a map of the field as a whole. Rather, it simply shows connections between the topics that we explore in this Forum. Despite this qualification, the figure still points to two findings of interest. First, the positioning of categories reinforces the idea that the study of peace and conflict is broadly divided between research on processes of violent conflict and studies of responses to conflict. The limited number of citation links that connect the (yellow) articles in clusters that we have categorized as 'Conflict and Civil War', on one hand, with the clusters of (pink) articles that we have categorized as 'Peacebuilding' and the cluster of (dark blue) articles labelled 'Transitional Justice', on the other, reflects this trend. The yellow nodes evidently represent a network of conflict-related articles, while the pink and dark blue clusters are collections of articles that consider responses to conflict. While there are certainly some links between the former and the latter, those connections are limited in number.

Figure 1: Categories of Citation Clusters, and Connections between Categories

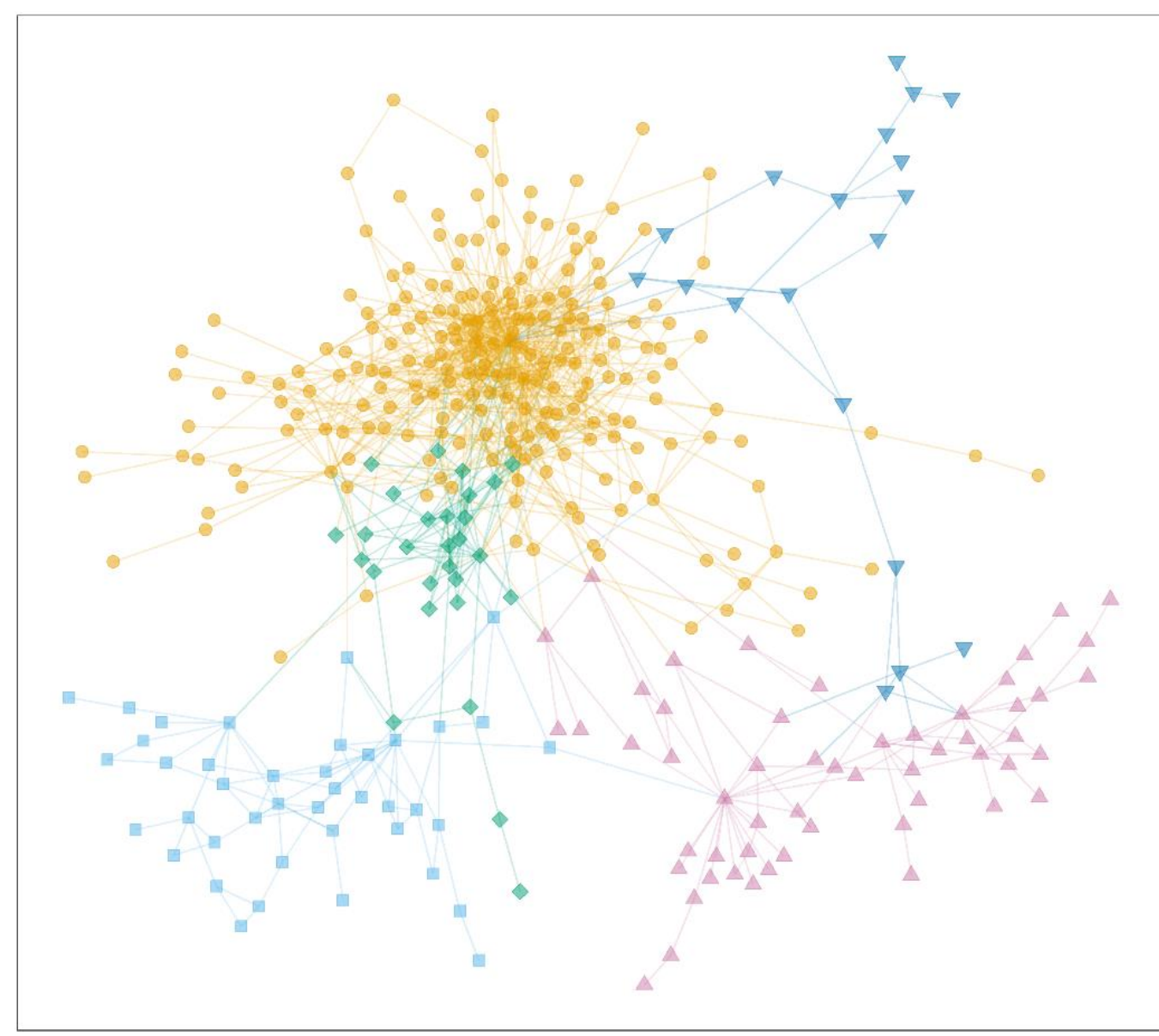

Conflict and civil war

Gender

Nonviolent resistance

$\triangle$ Peacebuilding

$\nabla$ Transitional justice 
Second, the graphic highlights an overall tendency toward intellectual siloes within the field; studies of particular topics tend to cite other similar studies, while connections between the topics explored in this Forum are limited. Not only are there few links between 'Conflict and Civil War' and most surrounding categories, there are also only limited connections between each of those peripheral categories. That is, there are few connections between articles that explore issues of 'Gender', 'Peacebuild ing', and 'Transitional Justice', respectively. There is, however, one clear exception to the pattern of disconnection, which is evident in the proximity of the cluster of (turquoise/green) articles labelled 'Nonviolent Resistance' to the clusters of (yellow) articles that we have labelled 'Conflict and Civil War'. This positioning and the visible links between turquoise and yellow nodes indicate that there is a degree of intercitation and, thus, intellectual exchange between studies of nonviolent resistance and research on violent insurgency.

\section{Implications for the 'State of the Discipline'}

Overall, various mapping projects in the field, including ours, point to three broad conclusions. First, studies of violent conflict dominate the field; not only do scholars produce more studies of violent conflict than studies of prevention/response, but works that address war/making receive more citations than do studies of peace/making. Second, there is only limited intellectual exchange between studies of peace-related topics and studies of war/violence. This lack of mutual engagement gives some credence to the idea that the field could be fairly described as peace or conflict studies, rather than peace and conflict studies. Third, on both sides of the putative peace/conflict divide, there appears to be a high degree of specialization within the field; scholars produce research that engages with other studies of similar topics rather than studies of other issue areas related to peace and conflict.

From an empirical perspective, these trends are neither welcome nor unwelcome; they simply indicate what we do and how we do it. From a more normative perspective, however, it is worth reflecting on what these trends tell us about the capacity of scholars of peace and conflict to realize their collective goal of studying violence to contribute to peace.

Some observers may not see specialization in the field as a point of concern; rather, specialization could indicate that the (still relatively new) discipline of peace and conflict studies is maturing and institutionalizing. When diverse scholars came together more than fifty years ago to establish publications such as the Journal of Conflict Resolution and the Journal of Peace Research, there were no competing journals. Now, however, there are tens of 
specialist journals that address issues of peace, conflict, and security. Equally, there is a vast number of academic chairs, programs of study, conferences, and professional associations that address these issues. Thus, the study of peace and conflict has come very far, very fast. As the discipline has institutionalized, so too has there been a rationalization of the work that we produce. This has naturally led to specialization and sub-specialization. Therefore, in addition to pan-disciplinary publications, there are now (often multiple) journals that focus on each of the specific topics that we discuss in this Forum; consider publications such as Civil Wars, International Peacekeeping, the International Journal of Transitional Justice and, most recently, the Journal of Resistance Studies, alongside a host of further publications that focus on other specialist areas. In terms of scientific progress, the specialization evident in these journals is arguably a force for good; it invites a focused study of significant topics and encourages the formation of communities of scholars who hold similar interests and/or use similar methods - both of which facilitate the kind of healthy academic debates that can drive research forward. Those debates, in turn, can contribute to the development of increasingly sophisticated knowledge across all areas of investigation, on both the peace and conflict sides of the discipline.

An alternate perspective, however, would be less optimistic about the merits of specialization, arguing that it leads to intellectual 'siloes' which, in turn, create barriers to communication and exchange between scholars. While such an outcome may be undesirable within any academic discipline, it can be seen as particularly problematic within peace and conflict studies, where 'siloization' is arguably preventing scholars from realizing the field's ontological goal of connecting studies of war/making with the praxis of peace/making. Consider the study of civil war and insurgency, for example. While there have been signific ant advances over the past twenty years in the way we understand the macro- and micromechanisms of collective violence, those advances have primarily been shared with, and appreciated by, scholars of violence and conflict (as evidenced in Figure 1). Consequently, sophisticated studies of war have had limited impact, at best, on the way that peace scholars and practitioners think about conflict prevention and response. Conversely, the study of postconflict peacebuilding has become something of an academic cottage industry over the past decade or so, and yet both students and practitioners of peacebuilding typically only give limited consideration to the vast corpus of literature that attends to the causes of violent conflict (again, as seen in Figure 1). As a result, post-conflict reconstruction is often analyzed, and practiced, in the absence of a rich knowledge of the dynamics of wartime destruction. 


\section{Breaking Down Siloes}

If rationalization and associated siloization are undermining the potential for peace and conflict scholars to realize the founding goals of their discipline, what might be done to encourage intra-disciplinary connections and intellectual exchange? A combination of actions by individual scholars and the 'gate-keepers' of the discipline offers possible remedies.

At the individual level, scholars could - and arguably should - make more of an effort to reach out and connect with studies that fall beyond their own finite areas of investigation. Thus, scholars studying insurgency, civil war, terrorism, and other conflict-related topics should not merely satisfy themselves with explaining the causes and dynamics of those outcomes. Rather, following the production of causal accounts, deliberate efforts could be made to connect those accounts with works that explore the nature and efficacy of preventive and/or responsive interventions. On the other side of the disciplinary divide, scholars whose work attends to the efficacy of direct and structural conflict prevention, peacebuilding, and post-conflict reconciliation could do more to build their assessments of these 'conflict resolution' efforts on thorough understandings of the nature of the conflict dynamics that are to be resolved.

One problem with this proposition is that there are currently few institutional incentives for scholars to reach across the peace/conflict divide because journals, grant-making bodies, tenure committees, and doctoral programs often reward specialization, rather than pandisciplinary connection. However, if the gate-keepers of the discipline - which include journal editors, funders, and research supervisors - recognize the need for a greater level of communication between studies of peace and studies of conflict, then they could shift incentive structures in a way that would encourage further intra-disciplinary exchange. For journal editors, this would mean actively encouraging, or even soliciting, studies that do not just 'make sense' of violence but, instead, also consider the implications of that sense-making for peace. For funding bodies, this would mean offering support for projects that aim to connect understandings of conflict with understandings of conflict resolution, rather than supporting studies of the former alone (as is sometimes the case with projects funded by government agencies) or the latter (as is sometimes the case with projects supported by intergovernmental agencies and non-governmental funders) (see discussion in Woodward 2007). Finally, supervisors of student research could encourage young scholars to integrate the connection between peace and conflict into their work from the very outset of their careers, before the sunk costs associated with over-specialization become difficult to reverse. 


\section{Contributions to this Forum}

The contributions to this Forum explore some of the issues raised in this introductory piece in further detail by considering how (perceived) intellectual divides within the discipline shape the output and impact of peace and conflict studies.

The two contributions that immediately follow look at how studies of conflict responses engage with studies of conflict processes, and the consequences of that (dis)engagement. The first piece comes from Roger Mac Ginty, who challenges the idea that there is a clear divide between studies of violent conflict and studies peacebuilding, in particular, before offering a series of optimistic views on the future direction of peace and conflict studies. The second piece comes from Denisa Kostovicova, who suggests that studies of post-conflict transitional justice often exist in isolation from studies of the conflictual contexts in which violations take place. She then argues that more engagement between studies of transitional justice and conflict dynamics could strengthen both the theory and practice of transitional justice and reconciliation.

The next two contributions shift the lenses of analysis and focus on areas of investigation that do not neatly fit into either the 'peace' or 'conflict' categories. Thus, they could serve as potential bridges between the two nominal pillars of the field. Drawing on lessons learned from extensive fieldwork, Annette Idler offers her thoughts on what studies of the gendered aspects of a conflict can teach us about the causal dynamics of conflict and, consequently, peacebuilding. Cassy Dorff then focuses on the study of nonviolence and argues that an exploration of civilian agency and nonviolent resistance promises to enrich our understanding of conflict and resistance broadly, as a first step toward what she calls the 'cultivation of peace'.

The Forum closes with a contribution from Keith Krause, who presents a genealogy of peace and conflict research. He argues that positivist, often quantitative, studies of the causes and dynamics of collective violence have come to hold a hegemonic position within the field. He then looks beyond 'mainstream' peace and conflict research and, in so doing, identifies approaches that could allow peace and conflict scholars to produce work that has the potential to not only build academic knowledge, but also emancipate and transform social relations.

\section{Works Cited}

Bright, Jonathan and Gledhill, John. 2018. A Divided Discipline? Mapping Peace and Conflict Studies. International Studies Perspectives 19(2): 128-147.

Bufacchi, Vittorio. 2005. Two Concepts of Violence. Political Studies Review 3(2): 193-204. 
Buzan, Barry and Hansen, Lene. 2009. The Evolution of International Security Studies. Cambridge: Cambridge University Press.

Diehl, Paul F. 2016. Exploring Peace: Looking Beyond War and Negative Peace. International Studies Quarterly 60(1): 1-10.

Fortunato, Santo. 2010. Community Detection in Graphs. Physics Reports 486(3-5): 75-174.

Galtung, Johan. 1969. Violence, Peace, and Peace Research. Journal of Peace Research 6(3): $167-191$.

Galtung, Johan. 1985. Twenty-Five Years of Peace Research: Ten Challenges and Some Responses. Journal of Peace Research 22(2): 141-158.

Goertz, Gary, Diehl, Paul F., and Balas, Alexandru. 2016. The Puzzle of Peace: The Evolution of Peace in the International System. New York: Oxford University Press.

Gleditsch, Nils Petter, Nordkvelle, Jonas, and Strand, Håvard. 2014. Peace Research - Just the Study of War? Journal of Peace Research 51(2): 145-158.

Kelman, Herbert C. 1981. Reflections on the History and Status of Peace Research. Conflict Management and Peace Science 5(2): 95-110.

Klein, James P., Goertz, Gary, \& Diehl, Paul F. 2008. The Peace Scale: Conceptualizing and Operationalizing Non-Rivalry and Peace. Conflict Management and Peace Science 25(1): $67-80$.

Lopez, George A. 1985. A University Peace Studies Curriculum for the 1990s. Journal of Peace Research 22(2): 117-128.

Regan, Patrick M. 2014. Bringing Peace Back In: Presidential Address to the Peace Science Society, 2013. Conflict Management and Peace Science 31(4): 345-356.

Rosvall, M., Axelsson, D., and Bergstrom, C. 2009. The Map Equation. European Physical Journal Special Topics 178(1): 13-23.

Sillanpää, Antti, and Koivula, Tommi. 2010. Mapping Conflict Research: A Bibliometric Study of Contemporary Scientific Discourses. International Studies Perspectives 11(2): 148-171.

Vasquez, John A. 1976. Toward a Unified Strategy for Peace Education: Resolving the Two Cultures Problem in the Classroom. Journal of Conflict Resolution 20(4): 707-728.

Wallensteen, Peter. 2011. The Origins of Contemporary Peace Research. In Understanding Peace Research: Methods and Challenges, edited by Kristine Höglund \& Magnus Öberg, pp. 14-32. Abingdon: Routledge.

Woodward, Susan L. 2007. Do the Root Causes of Civil War Matter? On Using Knowledge to Improve Peacebuilding Interventions. Journal of Intervention and Statebuilding 1(2): 143-170. 